\title{
As representações sociais de envelhecimento masculino e as diferentes vivências da sexualidade
}

\author{
Laura Maria Monteiro Maravilha*, Maria de Fátima de Souza Santos** \\ Raimundo Gouveia"** Angela Maria de Oliveira Almeida ${ }^{* * * *}$
}

\section{Resumo}

Este estudo tem como objetivo investigar, com base na teoria das representações sociais (TRS), as teorias de senso comum - que circulam entre homens heterossexuais e homossexuais - acerca do enveIhecimento. A TRS busca compreender as teorias leigas sobre determinados objetos sociais, construídas e compartilhadas de maneira coletiva, que orientam o comportamento dos indivíduos. Participaram deste estudo 16 homens com idade superior/ igual a 70 anos de idade, dos quais oito heterossexuais e oito homossexuais. Para a coleta dos dados, foi utilizada a entrevista narrativa, para análise e interpretação, utilizou-se o software Alceste. Foi observado que a orientação sexual em si não é determinante para a formação de representações sociais distintas sobre o envelhecimento; o lugar comum entre esses mundos aparentemente diferentes é a experiência da solidão, independentemente do tipo de relação conjugal que tenham construído e parecem ir além das relações afetivo-

\begin{abstract}
-sexuais, instalando-se principalmente nas pertenças grupais ou na falta delas. A sexualidade aparece como princípio organizador das práticas sociais que diferenciam os grupos. Para os homossexuais, as mudanças estéticas e a diminuição do vigor sexual os instigam a práticas de reparação do corpo. Para os heterossexuais, o declínio no desempenho sexual é encarado com conformismo e naturalidade, já que a prática sexual legitimada socialmente perde sua função com o fim da capacidade reprodutiva. Portanto, o estudo chama a atenção para a necessidade de considerar as singularidades humanas no intuito de conseguir compreender as diversas formas de envelhecimento e, consequentemente, as diferentes formas de abordagem e de apoio que o fenômeno requer.
\end{abstract}

Palavras-chave: Envelhecimento. Heterossexualidade. Homossexualidade. Representação social.

* Mestre em Psicologia pela Universidade Federal de Pernambuco. Professora do curso de Psicologia no Centro Universitário CESMAC - AL.E-mail: laura-maravilha@hotmail.com

** Doutora em Psicologia pela Universidade de Toulouse Le Mirail (França). Professora Titular da Universidade Federal de Pernambuco Departamento de Psicologia e Programa de Pós-graduação em Psicologia. Endereço para correspondência: Universidade Federal de Pernambuco Centro de Filosofia e Ciências Humanas. Av. da Arquitetura, s/n Departamento de Psicologia, 9o andar - Recife - PE CEP: 50740-550. E-mail: fatimasan@uol.com.br

*** Doutor em Psicologia Social pela Universidade Federal da Paraíba. Professor adjunto do. Instituto de Psicologia da Universidade Federal da Bahia.E-mail: raigouveia@gmail.com.

**** Doutora em Psicologia pela Universidade Católica de Louvain (Bélgica). Pesquisadora colaboradora sênior do Programa de Pós-Graduação em Psicologia Social, do Trabalho e das Organizações, do Instituto de Psicologia da Universidade de Brasília. E-mail: aalmeida54@gmail.com

$\rightarrow$ http://dx.doi.org/10.5335/rbceh.2013.1905 


\section{Introdução}

Em 1940, a esperança de vida do brasileiro sequer atingia os 50 anos de idade. Os avanços da medicina e as melhorias nas condições gerais de vida da população concorreram para que, sessenta anos mais tarde, em 2008, esse indicador atingisse 72,86 anos. Segundo a projeção de população do IBGE, em 2050 esse indicador deverá chegar aos 81,29 anos. Araújo, Coutinho e Santos (2006) destacam que, segundo a Organização Mundial de Saúde (OMS) (2005), o Brasil será o sexto país com maior número de pessoas idosas até 2025, o que torna urgente as investigações que contribuam para melhoria e/ou manutenção da saúde e qualidade de vida nessa faixa etária, considerando, principalmente, que esse crescimento provoca mudanças em uma proporção geométrica, enquanto a preparação para essa metamorfose ocorre em proporções aritméticas.

Nessa perspectiva, interessou-nos examinar o lugar da sexualidade no processo de envelhecimento, assunto particularmente "contaminado" por preconceitos. As crenças em torno da sexualidade dos idosos estão associadas ao ostracismo que os atinge nas diversas esferas sociais. Essas crenças parecem ter origem na ideia de que, no envelhecimento, a atividade sexual perde fatalmente seu objetivo de procriação e, portanto, sua justificativa social. Vasconcelos et al. (2004) assinalam que dentre as múltiplas exigências adaptativas que as alterações do envelhecimento comportam, os indivíduos enfrentam dificuldades para preservar a identidade pessoal e a integridade de alguns papeis e funções, sobretudo aqueles relativos à sexualidade que a sociedade atentamente vigia e sanciona. Biasus, Damantova e Carmago (2011), ao levantarem as representações sociais de envelhecimento e sexualidade entre homens e mulheres com mais de 50 anos, constataram que apesar desses dois objetivos serem representados de forma distinta, guardam relações entre si, podendo influir mutuamente nos comportamentos, pensamentos e reações desses indivíduos na vida cotidiana.

O corpo envelhecido é quase sempre visto como um corpo diáfano e desprovido de sensualidade e desejo. Com uma visão restrita, tanto em relação à sexualidade quanto à velhice, a sociedade, muitas vezes, classifica esse período da vida como um período de assexualidade e até de androginia, isto é, um período em que o indivíduo teria que assumir unicamente o papel de avó ou avô, cuidando de seus netos, fazendo tricô e vendo televisão. Não raramente, a sexualidade do idoso está contida no rol dos atos de caráter pecaminoso e maléfico.

La cuestión del erotismo en la vejez remitirá a los límites ajustados de un deseo circundado por la vergüenza, la fealdad, la idea de pérdida, la envidia, la venganza y fundamentalmente, por la disociación entre erotismo y muerte1 y por la fuerte asociación entre esta última y la vejez. (IACUB, 2004, p. 84).

Como o ato sexual foi naturalizado por sua funcionalidade, para procriação, naturalizou-se também uma escala temporal, na qual a atividade sexual foi inscrita, não podendo começar demasia- 
damente cedo, nem prolongar-se até muito tarde, em outras palavras, crianças e idosos são naturalmente assexuados. (OLIVEIRA et al. 2007).

É interessante observar que a suposição de uma velhice "inútil" e "doente" expande-se, inclusive, para a área da sexualidade do idoso. A pesquisa de Santos (1994) expressa isso, pois, ao serem questionados sobre o tema, os sujeitos afirmavam que namoro e casamento entre os idosos eram "safadeza", "fogo demais". Tais significados parecem estar respaldados na moral cristã, formadora da cultura brasileira, em que a sexualidade apenas justifica-se para a procriação. A sexualidade na velhice, entretanto, estaria desvinculada da possibilidade de gerar filhos e por isso mesmo é considerada em seus aspectos interacionais de companheirismo e amizade ou como algo "pecaminoso" ("safadeza", "sem-vergonhice"), afastando-se, assim, da procriação. (SANTOS; ALMEIDA, 2004). Dessa forma, a ideia de ser velho parece estar ligada à perda da vivência sexual. Arcoverde (2006), entretanto, sublinha que a sexualidade é uma característica humana que não se perde com o tempo e, conforme a história vivenciada pelo corpo vivente, essa vai se desenhando na trajetória existencial. A escassa literatura sobre a compreensão da sexualidade do idoso, que transcende a concepção biológica, aliada ao grande contingente de publicações referentes à sexualidade, sobretudo na adolescência e em adultos jovens, ratifica o caráter assexuado atribuído socialmente ao idoso, não sendo capaz de traduzir a pluralidade de vivências das sexualidades.
Em geral, os trabalhos sobre envelhecimento humano são realizados com a população heterossexual. A relação envelhecimento e homossexualidade masculina é ainda incipiente no universo acadêmico. Em pesquisa realizada no banco de teses da Capes, observou-se que até 2010 apenas três trabalhos relacionam homossexualidade e envelhecimento, sendo dois sobre reflexões do envelhecer em homossexuais femininas (BIER, 2004; LIMA, 2006). Tais dados reforçam a importância de se conhecer as concepções que os homossexuais possuem do envelhecimento, suas estratégias de enfrentamento para lidar com essa fase da vida e as implicações de sua orientação sexual sobre suas vivências sexuais.

Os idosos dos quais se falam, os quais se escutam e para os quais se constroem conhecimentos sobre o envelhecimento estão majoritariamente situados na norma heterossexista da sociedade. Envelhecimento e sexualidade são comumente tratados na base de um problema, seja de ordem social, médica ou moral. Os apelos contemporâneos da busca da beleza, do vigor físico e sexual, bem como da inserção social a partir de modelos normativos, parecem destituir o idoso do lugar de ser sexuado, notadamente, indivíduo sexuado de livre expressão, de desejos tão plásticos quanto a própria noção de desenvolvimento humano.

Confirmando essa perspectiva, Brigeiro e Maksud (2009) realizaram um estudo com o objetivo de avaliar o tratamento dado pela mídia jornalística ao aparecimento do Viagra ${ }^{\circledR}$ no cenário brasileiro. Nessa pesquisa, fica evidente a ideia veiculada pelos jornais de uma 
velhice assexuada que encontra numa "pílula do prazer" a possibilidade de continuar dispondo da sua sexualidade, antes condenada a um triste fim. Outro relevante dado do estudo é que nas 138 matérias analisadas, há apenas uma única menção à homossexualidade.

Diante da tendência de a sociedade, assim como a literatura científica, tratar o envelhecimento em uma perspectiva heteronormativa e assexuada, resta-nos aqui perguntar: quais as representações sociais de velhice construídas por sujeitos que pertencem a grupos sociais distintos do ponto de vista de sua sexualidade? A sociedade brasileira passa atualmente por transformações que acompanham uma tendência mundial de envelhecimento dos povos. O processo de envelhecimento, entretanto, não é homogêneo, mas marcado por heterogeneidades que raramente são traduzidas em números. Trazer à tona uma discussão sobre envelhecimento a partir de identidades hetero e homossexuais vai ao encontro da tendência atual em apontar a necessidade de conhecimento e atenção à população que envelhece, sem perder de vista as especificidades de sujeitos e grupos sociais. Diante do panorama apresentado, propõe-se, com esta pesquisa, discutir o envelhecimento enquanto fenômeno psicossocial, considerando de modo especial as diferenças que orientações sexuais distintas podem ou não trazer ao processo de envelhecimento de homens a partir de 60 anos de idade. Busca-se, pois, entender as aproximações e tensões nas representações sociais do envelhecimento de heterossexuais e homossexuais.
A teoria das representações sociais (TRS), formulada por Moscovici (1961), busca compreender como o homem comum apreende o conhecimento elaborado cientificamente. De acordo com Jodelet, as representações sociais (RS) são "uma forma de conhecimento, socialmente elaborada e partilhada, com um objetivo prático, e que contribui para a construção de uma realidade comum a um conjunto social." (2001, p. 22). Portanto, saber quais as representações que esses indivíduos têm sobre o envelhecimento, conforme sua identidade sexual, pode possibilitar a compreensão do significado conferido aos seus arranjos sociais nas relações amorosas, familiares, fraternas e consigo mesmo para a velhice.

\section{Método}

Compuseram o grupo de entrevistados 16 homens com idades a partir de 60 anos. Adotou-se aqui o critério estabelecido pela Organização Mundial de Saúde (OMS), que considera a idade de 60 anos como marco inicial da categoria idoso, em países em desenvolvimento como o Brasil. Nesse grupo, oito declararam-se homossexuais e oito declararam-se heterossexuais. As categorias de heterossexualidade e homossexualidade foram estabelecidas segundo a condição, declarada no momento da entrevista pelo sujeito, de prática ou interesse afetivo e/ ou sexual exclusivamente por pessoas do sexo oposto ou do mesmo sexo, respectivamente. Os idosos foram convidados a colaborar com a pesquisa independente de estado civil, nível de escolaridade, profissão, religião, raça/cor ou nível socio- 
econômico, após anuência e assinatura do Termo de Consentimento Livre e Esclarecido (TCLE). O projeto foi submetido e aprovado pelo Comitê de Ética do Centro de Ciências da Saúde da Universidade Federal de Pernambuco (Processo número CEP/CCS/UFPE 165/08).

Os participantes responderam a uma entrevista aberta do tipo narrativa, ou seja, uma entrevista que se apresenta como uma situação que encoraja e estimula o entrevistado a contar história(s) sobre algum acontecimento importante de sua vida e do contexto social. A entrevista narrativa é considerada uma forma de entrevista em profundidade, não estruturada. (JOVCHELOVITCH; BAUER, 2007). Como a entrevista narrativa dispensa a existência de um roteiro estruturado, existindo apenas um guia com perguntas geradoras sobre o tema, foi elaborado um guia básico para suscitar a fala dos informantes, contendo os seguintes temas geradores: envelhecimento, experiência de envelhecer, vivência de sua sexualidade. Todas as entrevistas foram gravadas com a autorização dos sujeitos.

Os entrevistados foram abordados a partir da rede de contato dos pesquisadores. A cada entrevista realizada, solicitava-se a indicação de outros sujeitos que concordassem em participar da pesquisa. Como a dificuldade maior referia-se à participação do grupo de homens homossexuais, foram realizadas inicialmente as entrevistas com esse grupo, cujo número de sujeitos determinou o número de homens heterossexuais que seriam entrevistados.

Após a transcrição literal das entrevistas, o corpus (conjunto de todas as en- trevistas reunidas em um só arquivo) foi submetido ao tratamento com o auxílio do software Analyse Lexicale par Contexte d'un Ensemble de Segment de Texte (Alceste). A técnica de análise lexical, realizada pelo Alceste, classifica um conjunto de palavras em um determinado contexto. Trata-se de um programa desenvolvido na França, por Max Reinert, em 1979 (REINERT, 1990), que permite a análise quali-quantitativa de dados textuais tomando como base as leis de distribuição do vocabulário (análises de cluster), por meio de diferentes etapas de segmentação do material discursivo (OLIVEIRA et al., 2003).

Os relatos dos homens hetero e homossexuais, obtidos por meio das entrevistas, foram processados em conjunto, configurando um único corpus de análise textual. A partir da identificação das unidades de contexto elementares (UCE) - fragmentos do corpus organizados pelo programa, de acordo com critério de pontuação e tamanho do texto -, o Alceste efetua uma classificação hierárquica descendente $(\mathrm{CHD})$, gerando um dendrograma (posicionamento das classes em forma de árvore), que permite a visualização da análise estatística realizada, com frequência e qui-quadrado das palavras representativas em cada classe, força de ligação entre as classes e porcentagem de cada classe em meio ao corpus analisado (BONOMO et al., 2008).

O dendrograma gerado pelo Alceste (Figura 1) possibilitou a análise das palavras contidas em cada classe e das respectivas UCE de onde elas foram extraídas. Desse modo, procuramos apreender o contexto de cada UCE e o 
sentido que ia sendo configurado a cada palavra e classe de palavras, bem como as variáveis mais características na formação de cada uma. Após analisar cada classe em separado e a relação de proximidade ou de distância entre elas, nomeamos cada uma e efetuamos a leitura das possíveis representações sociais que delas emergiam.

\section{Resultados}

O corpus de 16 unidades de contexto inicial (U.C.I.) ou entrevistas, após processado pelo software Alceste, foi dividido em 1.192 unidades de contexto elementar (U.C.E.), das quais 776 foram selecionadas na CHD, o que corresponde a $65,1 \%$ do total das UCE geradas ${ }^{1}$.
Essa análise produziu um dendrograma com quatro classes distintas de palavras (Figura 1), duas delas (classes 1 e 3) com maior relação entre si, são responsáveis por $23 \%$ do material analisado. Essas classes constituíram o eixo denominado "Vida social e corpo no processo de envelhecimento". Esse eixo indica as marcações simbólicas do envelhecer e suas inscrições no processo de envelhecimento, as quais são ressaltadas nos corpos e nas formas de se relacionar (social, afetiva e sexualmente) dos idosos participantes da pesquisa. Aqui se justapõem as ideias de envelhecimento como fenômeno natural e caracteristicamente marcado por perdas em nível físico, social e emocional.

Figura 1: Dendrograma resultante da CHD sobre o envelhecimento masculino

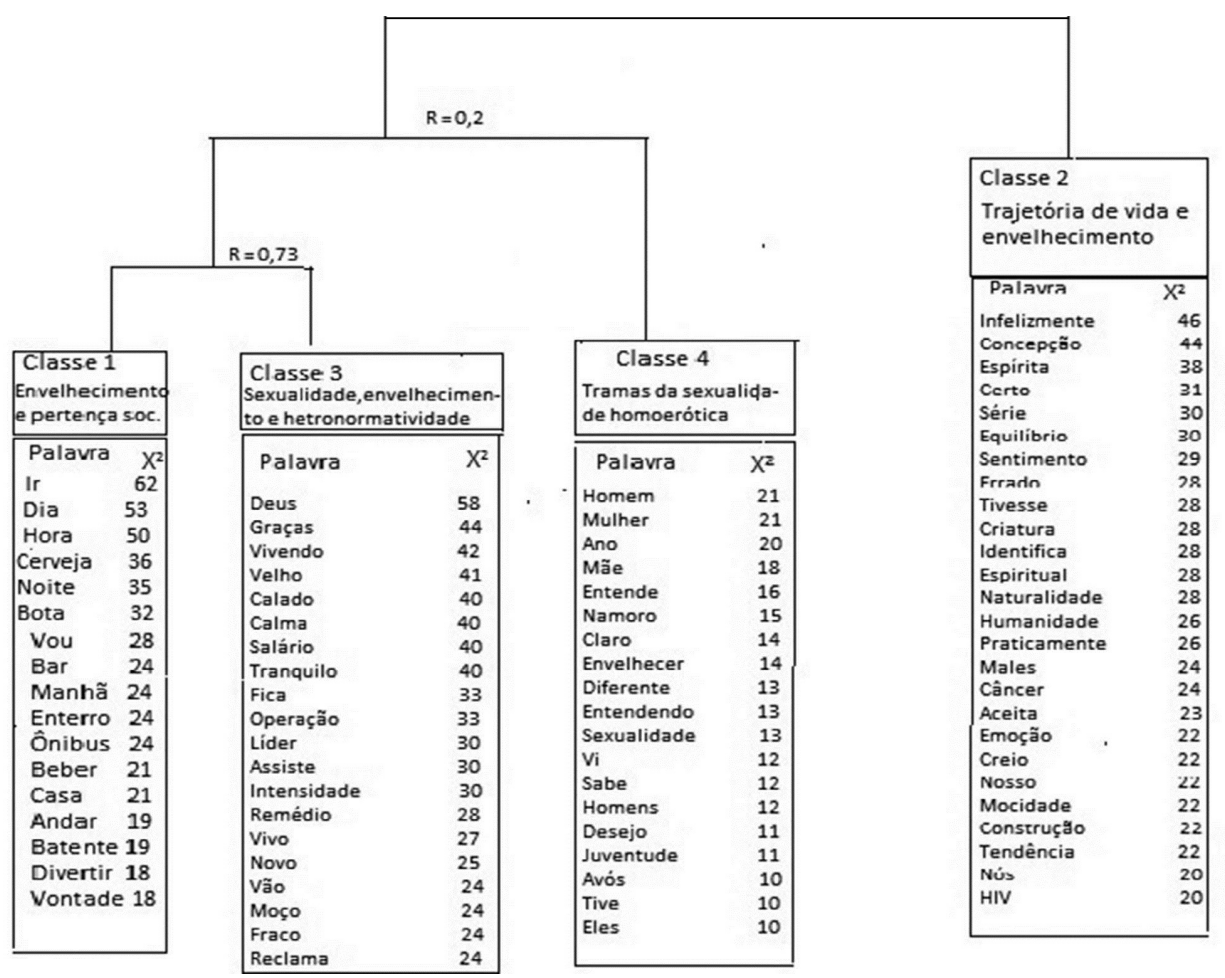


As classes 2 e 4, por outro lado, reúnem os discursos dos sujeitos sobre a sexualidade e o envelhecimento e são classes cujos sujeitos típicos declararam-se homossexuais. A classe 4 representa mais da metade do material analisado (56\%) e a classe 2 representa $20 \%$, as quais denominamos de "Sexualidade e envelhecimento". Nesse sentido, passa-se a analisar o conteúdo de cada classe, bem como seu papel na totalidade dos discursos.

Vida social e corpo no processo de envelhecimento

A classe 1 - Envelhecimento e pertença social - aponta para uma associação do envelhecimento ao declínio da vida social, culminando na produção de um isolamento do idoso, no qual se fusionam fatores motivacionais, físicos e culturais. As representações do envelhecimento se expressam por meio de um conjunto de situações e condições evocadas, as quais apontam para uma desaceleração do ritmo dos sujeitos na condução de suas vidas sociais. Nesse grupo, rotina e reclusão associam-se, uma vez que os idosos passam a maior parte do tempo em casa e sozinhos. Aqueles que ainda exercem uma atividade profissional encontram no ambiente de trabalho um espaço de socialização, muito embora acrescentem à vida profissional apenas a rotina da casa.

E eu não saio de casa, é de casa pro trabalho. Saio do trabalho, vou pra casa, escuto um pouquinho de música, escuto dois, três CDs, depois vou dormir (Hermes², 62 anos, homossexual).
[...] não aguentam ir pra boate, pra noitada, pra sair e amanhecer o dia e ele não aguenta fazer isso, nem eu também (Hipnos, 61 anos, homossexual).

As variáveis descritivas dessa classe indicam que ela foi formada por idosos heterossexuais e homossexuais, com nível de escolaridade médio (ensino médio completo) e que ainda exercem algum tipo de atividade produtiva, mesmo que de maneira informal. Aparentemente, não há uma diferença marcante entre heterossexuais e homossexuais quando se referem ao envelhecimento como fase da vida marcada por uma rotina monótona e um declínio da vida social. Algumas das palavras que mais contribuíram para a formação dessa classe, como, ir, dia, hora, dormir, noite, manhã, casa e vontade, expressam a vivência do tempo no ambiente domiciliar.

Essa classe revela o processo de produção coletiva de um isolamento social do idoso, pois, à medida que o envelhecimento é representado como declínio social, parece caber ao ser que envelhece apenas desenvolver e continuar nutrindo a competência social para pertencer ao grupo no qual está inserido. Se a competência não é atingida, acabamos por naturalizar a depressão social, física e emocional do idoso, sem darmo-nos conta de que a capacidade de adquirir uma competência de pertença é estabelecida numa troca entre o indivíduo e o grupo/ ambiente do qual faz parte. Conforme nos lembram Santos e Almeida (2004), a maior ou menor integração do sujeito idoso no mundo social depende também do contexto social em que se vive. O contexto social pode, nesse sentido, valorizar 
ou não certos tipos de comportamentos, limitar ou facilitar a utilização dos recursos individuais do idoso nas situações de mudança produzidas pela velhice.

A classe 3 - Sexualidade e envelhecimento no percurso da heteronormatividade - é constituída por 71 U.C.E., correspondendo a $9 \%$ do total do corpus analisado. Essa classe revela a relação entre envelhecimento e sexualidade, na perspectiva dos participantes heterossexuais. $\mathrm{O}$ envelhecimento é associado a uma fase da vida marcada pela diminuição da libido e das práticas sexuais, cujas justificativas envolvem desde razões físicas até culturais. A diminuição ou o fim de uma vida sexual ativa entre os participantes da pesquisa responsáveis pela formação dessa classe é atribuída, principalmente, a acometimentos de doenças da próstata, ao "esfriamento" ou à diminuição da libido, ao desinteresse sexual também da parceira e por vezes a uma conotação negativa dirigida ao desejo e à prática sexual nessa fase da vida.

O cabra novo tá preparado toda hora e cabra velho não, é... é mais difícil, porque o cabra tá velho, tá ficando fraco. Não é uma coisa natural mesmo, né? Tem que se conformar que quando era novo era uma coisa e hoje é outra. (Anúbis, 60 anos, heterossexual).

Mulher, isso é um esporte, é um vício, mas quando o cara tá velho procure seu lugar! Eu não tô certo? Tô certo! Olhe, a minha esposa é calma, ela operou-se, o médico disse que ela podia ter saúde pra outras coisa, mas pra ter mais filho não, ela ficou fria, ai acabou-se. (Anúbis, 60 anos, heterossexual).

Podemos perceber por meio das U.C.E. dessa classe que há entre os idosos heterossexuais certo conformismo em relação ao declínio sexual relatado. Essa nova configuração da sexualidade parece encontrar um lugar de acomodação no modelo heterossexual, no qual o casal envelhece junto e as mudanças decorrentes da idade não são questionadas, já que são compartilhadas pelo homem e pela mulher. Além disso, o sexo é praticado dentro da instituição social da família e do casamento, tendo cumprido na maioria das vezes a função procriativa e, por isso, aparentemente, a diminuição gradativa ou mesmo o abandono da prática sexual ganha ares de maior naturalidade nesse grupo.

De acordo com Vasconcellos et al. (2004), os estereótipos ligados à degradação biológica, que serviram durante séculos para caracterizar o processo do envelhecimento, continuam a impregnar o imaginário cultural. Na mesma direção, as repercussões do processo de envelhecimento sobre a sexualidade constituem um assunto particularmente relacionado a preconceitos.

As variáveis descritivas da classe demonstram que ela foi formada por idosos heterossexuais com nível de escolaridade fundamental completo e/ou incompleto, casados, que moram com suas esposas ou com outros parentes e são de religião predominantemente católica. As palavras que mais contribuíram para a formação da classe foram: velho, intensidade, remédio, novo, fraco, tranquilo e operação.

Sexualidade e envelhecimento

A classe 4-As tramas da sexualidade homoerótica - foi constituída por 436 U.C.E., o que corresponde a $56 \%$ do total do corpus analisado. Essa classe revela a 
relação entre envelhecimento e sexualidade no universo homossexual, no qual questões relacionais, físicas e estéticas ganham uma dimensão valorativa extrema para a manutenção da vida sexual. No entanto, a relação envelhecimento e sexualidade visualizada aqui não se refere apenas a uma relação direta com a prática sexual, como no grupo de heterossexuais, mas do universo que permeia a sexualidade homossexual, tais como a afirmação social, os receios da velhice e a identidade homoerótica.

Hoje é diferente né, você envelhecer como homossexual, hoje é tudo diferente, mas eu tento criar uma estrutura na minha vida, pra o futuro, porque existe essa particularidade, quando você casa e tem filhos.

Eu sou gay e não gosto de travesti, eu sou homem que gosta de homem, eu não quero ser mulher nunca, eu quero ser homem que gosta de homem! Entendeu? Eu acho que mulher é uma coisa divina, uma coisa pura, se bem que tem muitas homem, né? (Hefesto, 60 anos, homossexual).

Este último trecho revela ainda os entraves do complexo mundo das sexualidades e das homossexualidades, no qual termos e comportamentos confundem-se e originam rusgas e opressões entre os oprimidos. Conforme assinalam Ribeiro et al. (2006), o preconceito dirigido a formas não convencionais de se viver a sexualidade é tão fortemente disseminado em nossa sociedade que, mesmo entre os homossexuais, existem atitudes marcadamente preconceituosas diante da própria homossexualidade, nas suas diversas expressões. Cita-se, por exemplo, o preconceito de gays contra lésbicas e vice-versa; de gays contra travestis, que terminam por perpetuar o ciclo da violência.

Nesse grupo, é possível perceber uma negação do envelhecimento e um valor pejorativo atribuído ao idoso, sobretudo pelas exigências de beleza e vigor físico presente nas relações homoeróticas. $\mathrm{O}$ envelhecimento é sentido muito mais nas mudanças estéticas decorrentes da idade e é na tentativa de reparação desse corpo que reside a maior negativa do envelhecer entre os homossexuais entrevistados:

[...] agora envelhecer tá associado ao físico também né? Você vai mudando, claro! A pele vai enrugando né, os cabelos brancos. Então é muito frustrante, muito decepcionante a gente conviver, porque já é um... não existe devido às exigências da beleza física, da beleza é... é... facial... e uma série de outras, então você é muito discriminado, muito menosprezado, aí fica difícil, não há uma aceitação no homossexual de... de idoso, é muito rejeitado. (Hipnos, 61 anos, homossexual).

As afirmações indicam que parece haver um parâmetro do envelhecer muito mais próximo do corpo em vez do sentimento, do mental, do espírito, da vontade, o que pode reforçar a hipótese de que o corpo tem um valor muito grande para essa parcela da população. O corpo que fala, que seduz, que é, que tem significado, que traz autoestima, que é o chamariz de si próprio. Podemos afirmar que o corpo tem e traz em si conceitos antigos de supervalorização, tendo papel na comunicação e nos encontros da vida social, e no envelhecimento adquire outro valor (MAKI, 2005).

A preferência por parceiros mais jovens é unanimidade entre os idosos homossexuais participantes da pesquisa e que declararam envolvimento afetivo 
e/ou sexual com alguém no momento da entrevista. Esse comportamento parece estar ligado a uma busca pela beleza e juventude por intermédio do outro, que lhe oferece os atrativos físicos desejados. Nesse contexto, aparecem os "casos-folha”, ou seja, a prática sexual está quase sempre permeada por uma negociação financeira, explícita ou não.

[...] não me vejo tendo relacionamento com adultos, com alguém com mais de trinta anos, não me vejo, não gosto! Até brincam comigo, sabe. Me chamam de pedófilo, mas só na brincadeira. (Dionísio, 60 anos, homossexual).

Essa classe é constituída exclusivamente por homossexuais, com nível de escolaridade superior completo e/ou incompleto, solteiros, que vivem com parentes ou com seus parceiros, exercem algum tipo de atividade laboral, estão se relacionando afetiva e/ou sexualmente no momento e declaram não possuir religião. As palavras que mais contribuíram para a formação da classe foram: homem, mulher, gay, namoro, envelhecer, diferente e sexualidade.

Trajetória de vida e envelhecimento

A classe 2 (responsável por $20 \%$ do total do corpus analisado) traz em sua formação uma ideia que se diferencia de todas as outras classes, enfatizando questões espirituais e míticas na formação de uma suposta representação do envelhecimento. Por ser constituída majoritariamente por U.C.E. de um único sujeito (apenas uma U.C.E. pertence à entrevista de sujeito diferente) e não pressupõe necessariamente a formação de um outro eixo, mas aparece de for- ma isolada e diferenciada das demais (Figura 1).

Analisando as respostas dos entrevistados, o envelhecimento aparece como o lugar das reflexões dos atos cometidos durante a vida, especialmente durante a juventude, além de se configurar como espaço para punições, recompensas e resgates espirituais. Podemos constatar a forte influência da religião, sobretudo da crença espírita. A homossexualidade aparece como causa de um envelhecimento com menor qualidade de vida e como motivação para punições e reparações espirituais. Essa opção sexual concretiza todo tipo de ação contrária à moral social e às leis divinas que podem acarretar sofrimento e punição para o ser humano no momento em que se aproxima da velhice.

[...] Muito embora, estou afastado há um bom tempo, mas o meu espírito é um espírito homossexual, as minhas tendências é de homossexualismo, agora eu não devia, eu me arrependo só de ter praticado e não ter partido pra algo melhor. (Apolo, 67 anos, homossexual).

Então, fatalmente, com certeza esses males não teriam vindo se eu tivesse dominado as tendências, se eu tivesse dominado as emoções, certo. (Apolo, 67 anos, homossexual).

\section{Conclusões}

Muito embora os objetivos deste estudo apontem para a busca das possíveis diferenças nas representações sociais do envelhecimento, entre homens com orientações hetero e homossexuais, o que primeiro chama a atenção em seus discursos é a semelhança no modo de ver 
e viver o processo de envelhecimento. Assim, o lugar comum entre esses mundos, aparentemente diferentes, é a experiência da solidão, independentemente do tipo de relação conjugal que tenham construído. Tal sentimento de solidão parece ir além das relações afetivo-sexuais, instalando-se principalmente nas pertenças grupais, ou, ainda, na falta dessas relações. Ao que parece, esse sentimento independe do modo como esses idosos vivem a sexualidade. De qualquer modo, a solidão, o isolamento social, abate a todos, independente da opção sexual.

Para os participantes que se identificam como heterossexuais, a sexualidade no envelhecimento parece perder seu papel, já cumprido em outras fases da vida. Embora se note algumas tentativas de transferir a responsabilidade do desinteresse sexual para as companheiras, eles próprios não se mostram muito afetados pelo declínio da frequência dos encontros sexuais. A referência aos arroubos da juventude serve para localizar a sexualidade no passado, na juventude perdida.

Para os que se identificam como homossexuais, ao contrário, a sexualidade ainda se apresenta como forma de afirmação social, servindo para fugir do estereótipo de velho. Junte-se a isso a estratégia de "corrigir" os sinais do tempo no próprio corpo. Parece permanecer nesses homens o desejo de continuar buscando uma companhia, mesmo que essa procura soe como algo artificial, como se vê nas relações que eles chamam de "casos-folha", ou seja, relações com homens mais jovens mantidas em troca de benefício financeiro.
Esses resultados permitem concluir que os homens heterossexuais, diante do envelhecimento, tendem a se retrair das possibilidades de vivência da sexualidade, justificado como um desdobramento natural do envelhecimento. Já os homens homossexuais, tendem a condicionar a vivência da sexualidade a uma imagem jovem. Diante da impossibilidade de se manter sempre jovem, seu destino o conduz ao mesmo movimento dos heterossexuais: ao retraimento da sexualidade. Por caminhos distintos, chegam ao mesmo lugar: o isolamento social e sexual.

Os discursos que compõem a classe 2 , ainda que remetam a um caso isolado, indicam, novamente, uma aproximação da experiência de envelhecimento entre homens homossexuais e heterossexuais. A diminuição da frequência das práticas sexuais nesse discurso é justificada por um desgaste moral herdado da juventude. A semelhança entre os dois grupos é mais clara e se estabelece a partir da preservação da identidade sexual. Esses homens mostram que as vivências dos idosos, embora tenham aspectos em comum, se diferenciam no significado a elas atribuído. No caso dos heterossexuais, a diminuição das práticas sexuais parece compor um quadro geral de conformismo diante do afastamento do mundo do trabalho e da diminuição da vida social. Já entre os homens com práticas homoeróticas, a vivência da sexualidade na velhice acentua ainda mais o estigma de uma prática considerada como antinatural e perversa, daí ser desejável e esperado que tais práticas cessem na velhice. 
Finalmente, ressalta-se aqui a importância de se poder extrair, a partir da análise desses discursos, as singularidades humanas que sustentam as diversas formas de significar e viver o envelhecimento e a sexualidade. Consequentemente, no campo de atuação profissional, devem-se levar em consideração essas diferenças, sobretudo nas abordagens que esses fenômenos requerem. Fica clara a necessidade de dar uma atenção maior à população masculina, indo ao encontro de políticas públicas que destacam a necessidade de uma atenção especial à saúde biopsicossocial dessa população. Outros estudos poderiam complementar esta pesquisa, particularmente aqueles que possam revelar como as pessoas comuns e os profissionais da saúde e assistência têm representado e lidado com a sexualidade na velhice.

\section{Social representations of aging male and different experiences of sexuality}

\section{Abstract}

This work had the purpose of investigating the ideas of common sense about aging between heterosexual and homosexual men, using the Social Representations Theory. The Social Representations Theory try to understand the naive theories about specific social objects, built and shared collectively and that orient the behavior of individuals. Sixteen sixty-year-old men participated in this study; eight of them were heterosexual and eight were homosexual. In order to obtain the data, we used narrative interviews, in order to analyze and interpret them, we used a software cal- led Alceste. We observed that the sexual orientation within itself is not a determinant of the formation of different social representations of aging. The common place of these apparently different worlds is the experience of solitude, independent of the type of relation that they built and it appears to transcend the sexual-affectionate relations, installing themselves especially among the group relationships or on the lack of them. Sexuality seems to be a organizational principle of social practices which differentiate groups. For homosexuals, the esthetic changes and the decrease of sexual vigor make them seek body reparations. For heterosexuals, the decrease of sexual action is seen with conformism and naturality, as social legitimated sexual action loses its function as the reproduction capacity comes to an end. The study, therefore, calls our attention on the necessity of considering the human singularities to try to understand the diverse forms of aging and, consequently, the different forms of analyzing and help that the phenomenon requires.

Keywords: Aging. Heterosexuality. Homosexuality. Social representation.

\section{Notas}

1 Uma melhor estabilidade de análise pode ser obtida com um percentual de $75 \%$.

2 Todos os nomes dos sujeitos são fictícios. 


\section{Referências}

ARAÚJO, L. F.; COUTINHO, M. P. L.; SANTOS, M. F. S. O idoso nas instituições gerontológicas: um estudo na perspectiva das representações sociais. Psicologia e Sociedade, Porto Alegre, v. 18, n. 2, p. 89-98, maio/ago. 2006.

ARCOVERDE, M. A. M. A percepção da sexualidade do corpo idoso. 2006. 88f. Dissertação (Mestrado em Enfermagem) - Programa de pós-graduação em Enfermagem - Universidade Federal do Paraná, Curitiba, 2006.

BIASUS, F.; DEMANTOVA, A.; CAMARGO, B. V. Representações sociais do envelhecimento e da sexualidade para pessoas com mais de 50 anos. Temas em psicologia, Ribeirão Preto, v. 19, n. 1, p. 319-336, jun. 2011. Disponível em: <http://pepsic.bvsalud.org/scielo. php?script=sci_arttext\&pid=S1413-389X201 $1000100025 \& \operatorname{lng}=p t \& n r m=i s o>$. Acessos em: 20 nov. 2013.

BIER, A. L. S. Sobre cinemas e vídeo-locadoras pornôs, províncias de outros corpos e outros significados. 2004. Dissertação (Mestrado em Antropologia Social) - Universidade Federal do Rio Grande do Sul, Porto Alegre, 2004.

BONOMO, M. et al. Representações sociais e identidade em grupos de mulheres ciganas e rurais. Psicologia, Lisboa, v. 22 , n. 1 , p. 153-181, 2008.

BRIGEIRO, M.; MAKSUD, I. Aparição do Viagra na cena pública brasileira: discursos sobre corpo, gênero e sexualidade na mídia. Estudos Feministas, Florianópolis, v. 17, n. 1, p. 296, jan./abr. 2009.

IACUB, R. Erotismo y vejez en la cultura greco-latina. RBCEH - Revista Brasileira de Ciências do Envelhecimento Humano, Passo Fundo, v.1, n.2, p. 84-103, jul./dez. 2004.

JODELET, D. (Org.). As representações sociais. Rio de Janeiro: UERJ, 2001. 416 p.
JOVCHELOVITCH, S.; BAUER, M. W. Entrevista narrativa. In: BAUER, M. W.; GASKELL, G. Pesquisa qualitativa com texto: imagem e som - um manual prático. 6. ed. Rio de Janeiro: Vozes, 2007, p. 90-113.

MAKI, M. A. Reflexões sobre o processo de envelhecimento em homossexuais masculinos. 2005. 125 f. Dissertação (Mestrado em Gerontologia) - Pontifícia Universidade Católica de São Paulo, São Paulo. 2005.

MOSCOVICI, S. La psychanalyse, son image et son public. Paris: PUF, 1961. 650 p.

OLIVEIRA, D. C. et al. Estudo das representações sociais através de duas metodologias de análise de dados. Revista de Enfermagem UERJ, Rio de Janeiro, v. 11, n. 3, p. 317-27, 2003.

OLIVEIRA, L. C.; OLIVEIRA, S. R. N.; IGUMA, L. T. O processo de viver nos filmes: Velhice, sexualidade e memória em Copacabana. Texto contexto Enfermagem, Florianópolis, v. 16, n.1, p. 157-62, jan./mar. 2007.

REINERT, M. Alceste, une méthodologie d'analyse des données textuelles et une application: Aurelia de Gerard de Nerval. Bulletin de Methodologie Sociologique, Paris, v. 26, n. 1, p. 24-54, 1990.

RIBEIRO, A. S. M. et al. A homossexualidade masculina: vivência e significados. In: ALMEIDA, A. M. O. et al. (Orgs.). Violência, exclusão social e desenvolvimento humano. Brasília: Editora da Universidade de Brasília, 2006. p. 261-299.

SANTOS, M. F. S.; ALMEIDA, A. M. O. Práticas sociais relativas ao idoso. Temas em Psicologia, Ribeirão Preto, v. 10, n. 3, p. 221-228, 2004.

VASCONCELLOS, D. et al. A sexualidade no processo do envelhecimento: novas perspectivas - comparação transcultural. Estudos de Psicologia, Natal, v. 9, n. 3, p. 413- 419, 2004. 